\title{
The Void Fabric Study of Sand Based on Image Processing Technology
}

\author{
Yang Guo ${ }^{1,2}$, Xuefeng $\mathrm{Li}^{2, *}$ and Daming Liu ${ }^{1}$ \\ ${ }^{1}$ School of Physics and Electrical Information, Ningxia University, Yinchuan 750021, China \\ ${ }^{2}$ Solid Mechanics Institute, Ningxia University, Yinchuan 750021, China \\ ${ }^{*}$ Corresponding author
}

\begin{abstract}
Sand is the discrete particle material in meso level and irregular distribution of sand void space is showed anisotropy. The reasonable description of this feature is important to study on sand strength and deformation mechanism, and the anisotropy of pore space is studied by using the directional distribution equation of the pore in this paper. Having the meso-experiment with the collected Aeolian sand which is from Tengger Desert, and performing image processing technology to the collected scanning electron microscope(SEM) image of samples to make it become binary image with clear boundary and particles separation. In order to extract the pore information in different directions from the binary image and calculate the pore distribution, we write Matlab image analysis program for directional distribution equation of the pore. We have proved that the Aeolian sand has obvious anisotropy of pore through the image analysis of the Tengger Desert samples.
\end{abstract}

Keywords—sand; void; fabric tensor; image processing; image analysis

\section{INTRODUCTION}

The local strain of soil body is a main cause of instability and progressive failure in geotechnical materials. The fabric model established through the combination of the microstructure and macroscopic stress of soil body can explain not only the macro-mechanical properties of soil body, but also the meso-principles of the soil mass structure in changes. With the rapid development of computer technology, digital image processing and analysis technology[1-3] have gradually become common tools for scholars to study mesomechanics of soil. Khalid[4] and Oda[5] make samples by using the mixed liquor of epoxy resin, observes with SEM, and collects pictures to analyze porosity distributions so as to study the anisotropy of sandy soil. Al-Shibli[6] puts forward a method to extract the porosity distributions in direction from images with the sample cutting method by using the image processing technology.

The main research objective of this paper is to put forward a simple and available meso-cracking distribution based sandy soil meso-fabric quantitative analysis method with the image processing and analysis technology through the combination of theories and experimental research, and further to carry out deeper research on anisotropy of sandy soil.

\section{TheORETICAL DESCRIPTION OF PORE FABRIC OF SAND SOIL}

The porosity direction distribution equation is shown as:

$$
N\left(n_{m}, \theta_{m}\right)=n_{m}\left(1+N_{i j} n_{i} n_{j}\right)
$$

Where $n_{m}$ refers to the average porosity; $\theta_{m}$ refers to the direction of the pore; $N_{\mathrm{ij}}$ refers to second order porosity fabric tensor; $n_{i}=\cos \theta_{m}, n_{\mathrm{j}}=\sin \theta_{\mathrm{m}} ;$ Below the twodimensional plane, the fabric tensor $N_{\mathrm{ij}}$ can be represented as:

$$
N_{i j}=\left[\begin{array}{cc}
A_{2} & B_{2} \\
B_{2} & -A_{2}
\end{array}\right]
$$

$$
n_{m}=\sum_{m=0}^{N-1} \frac{L_{L}\left(\theta_{m}\right)}{N}
$$

$$
\left[\begin{array}{l}
A_{2} \\
B_{2}
\end{array}\right]=\frac{2 \sum_{m=0}^{N-1} L_{L}\left(\theta_{m}\right)\left[\begin{array}{l}
\cos (2 \pi m / N) \\
\sin (2 \pi m / N)
\end{array}\right]}{\sum_{m=0}^{N-1} L_{L}\left(\theta_{m}\right)}
$$

$L_{L}\left(\theta_{\mathrm{m}}\right)$ represents the proportion of the test line occupied by pores, which can be obtained by AND operation of the test line and the binary image of the sample. When all the angles are obtained in $L_{L}\left(\theta_{\mathrm{m}}\right)$, we can obtain $n_{m}, \mathrm{~A}_{2}, \mathrm{~B}_{2}$ through (3) and (4), where $A_{2}$ and $B_{2}$ represent the degree of anisotropy of pore direction distribution. Finally, we can calculate the directional distribution of porosity $N\left(n_{m}, \theta_{m}\right)$ from (1) and use it to quantitatively study the anisotropy of granular materials.

\section{IMAGE ACQUISITION AND PROCESSING}

\section{A. Image Acquisition}

The shooting of SEM image taken from the appearance of the sample is shown as the Figure I, and on the sample surface, 
6 images are taken.

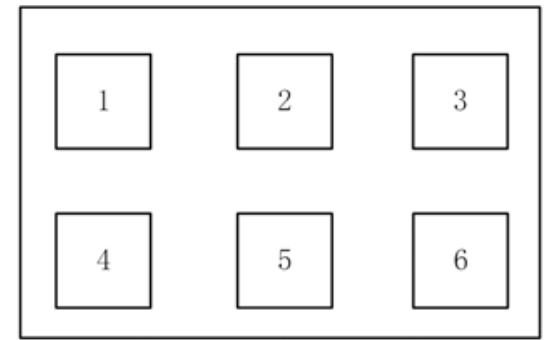

FIGURE I. CAPTURE LOCATION ON SAMPLE SURFACE

In this research, the images of the samples are only taken horizontally and vertically. As the volume of the sand particles is larger, overamplification will cause only one or two particles in the image taken and make it incapable to carry out porosity direction distribution. The amplification times adopted in this paper is 150 (See Figure II).

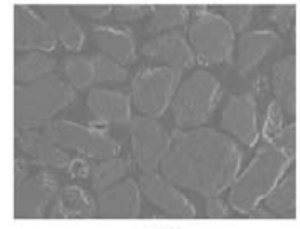

(a)

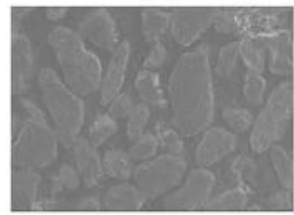

(c)

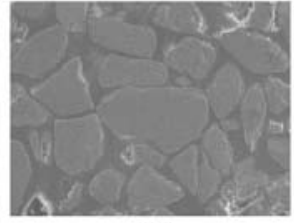

(b)

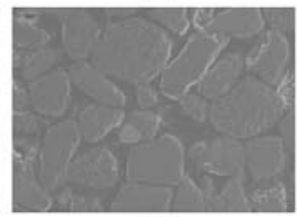

(d)
FIGURE II. SAMPLE IMAGE CAPTURED BY SEM

\section{B. Image Pre-processing}

1) Histogram equalization:

Histogram equalization refers to transfer the pixels of excessive concentration in some gray values in the images into those of average distribution, that is, all gray values of the pixels in the images should be within the gray level of 256 to heighten the luminance contrast[7].

\section{2) Median filtering:}

By observing the following figure (b), we can discover that there are textures different in brightness on the particle surface while some pixels in the black porosity background are mistaken as the white target points. As the total number of the interference points emerging in the image is not too much, this paper uses the method of median filtering to eliminate the catastrophe points in the image.

\section{3) Image segmentation:}

Image segmentation refers to set all gray values of pixels in the gray level images to be 0 or 1 to cause only two colors of black and white in all pixels. Generally speaking, the gray level images are changed into the binary images through the selection of threshold value. There are many methods to select from the threshold values such as double wave crests method and OTSU[8], etc. This paper adopts OTSU.
The principle of OTSU is to determine the threshold value $\mathrm{T}$ and classify the pixels into two areas: target area and background area. The variance between the two areas is calculated, and the differences between the two are the biggest when the variance reach its maximum and threshold value is optimal. This method is an automatic threshold selection method, time-saving with a more accurate value. The segmentation results are shown as figure (c) when the threshold value is 135 (See Figure III).

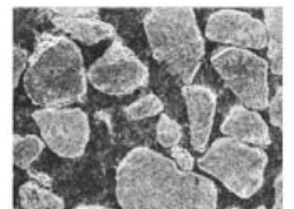

(a) Histogram equalization

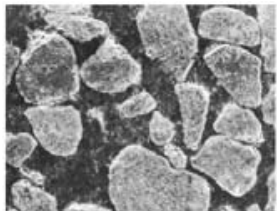

(b) Median filte

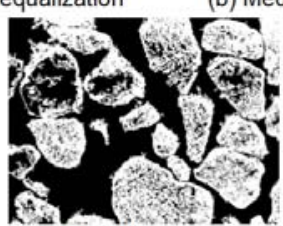

(c) OTSU method binary image

FIGURE III. IMAGE PRE-PROCESSING

\section{POROSITY DIRECTION INFORMATION EXTRACTION}

\section{A. The Image Analysis Method for Porosity Information Extraction}

Draw pictures of test lines of different angles, carry out AND operation of the test lines and the sample binary image to obtain the porosity of each test line in direction $L_{L}\left(\theta_{m}\right)$, and substitute $L_{L}\left(\theta_{m}\right)$ into (3) and (4) to calculate the average porosity $n_{m}$ and the two-dimensional tensor $N_{\mathrm{ij}}$. (See Figure IV)

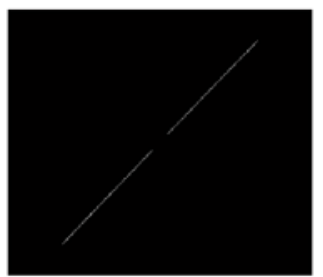

(a) Test line image

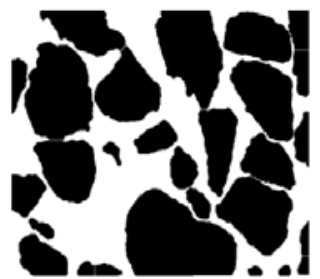

(b) Binary image of sample

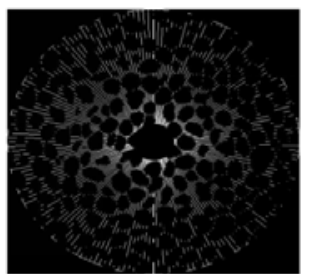

(c) Test line and pore intersection image

FIGURE IV. THE IMAGE OF PORE RATIO 
B. Mesoscale Experiment Analysis of the Sand Sample from Tengger Desert

The sample 1 and sample 2 are selected from Tengger Desert in this paper, and same method is adopted for sampling, cutting and surface processing. The intersection of the test lines and the sample images is obtained to extract porosity information of sand sample in different directions. The porosity distribution data obtained directly through the extraction from the test lines is trial value which is substituted into the traditional formula and then the data obtained is value of simulation. Under the polar coordinate system, the porosity direction distribution map of the samples is drawn.

The display of the analysis results of the sand sample from Tengger Desert is shown as (See Figure V Figure VIII):

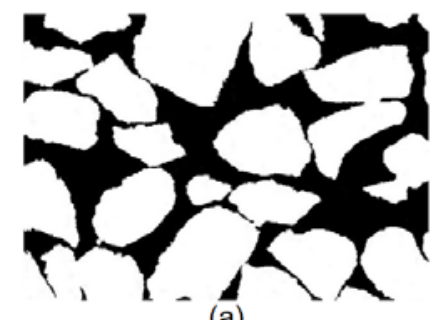

(a)

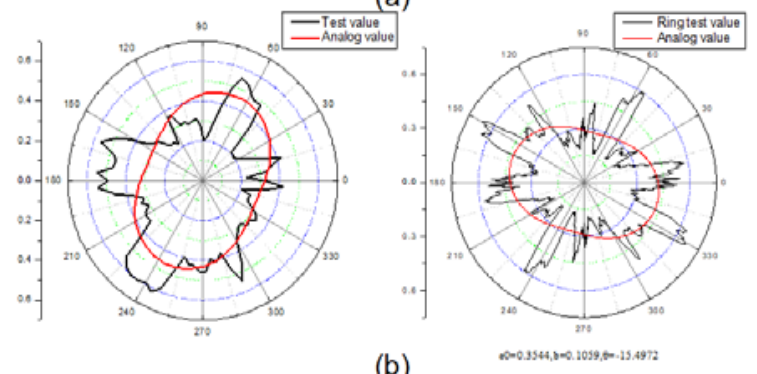

(b)

FIGURE V. SAMPLE 1 VERTICAL IMAGE AND DIRECTIONAL DISTRIBUTION CHART OF PORE ON VERTICAL

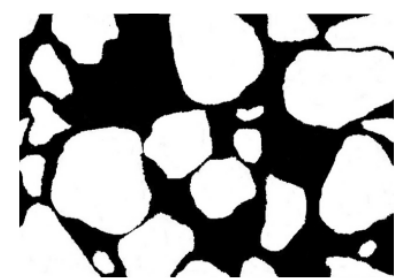

(a)
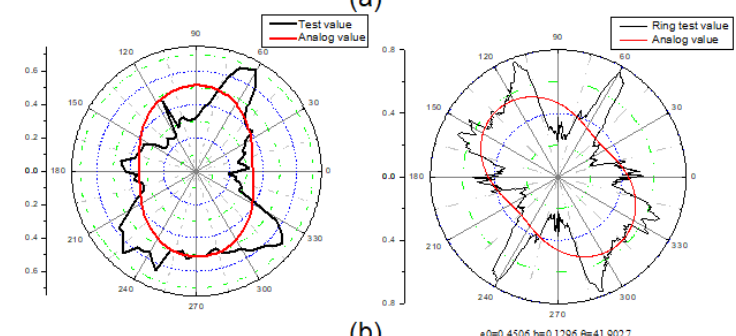

(b)

FIGURE VI. SAMPLE 1 HORIZONTAL IMAGE AND DIRECTIONAL DISTRIBUTION CHART OF PORE ON LEVEL

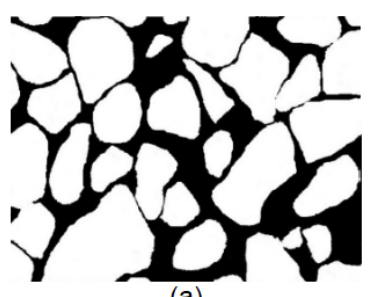

(a)

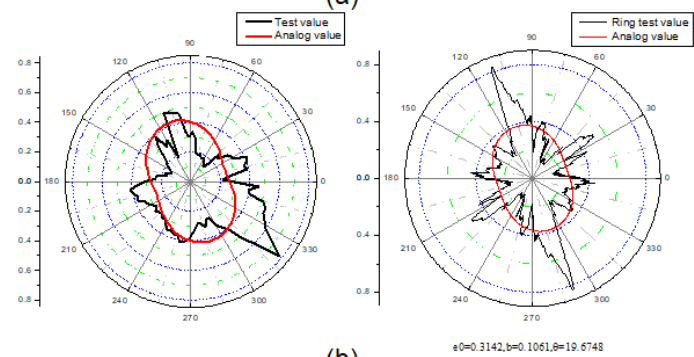

(b)

FIGURE VII. SAMPLE 2 VERTICAL IMAGE AND DIRECTIONAL DISTRIBUTION CHART OF PORE ON VERTICAL

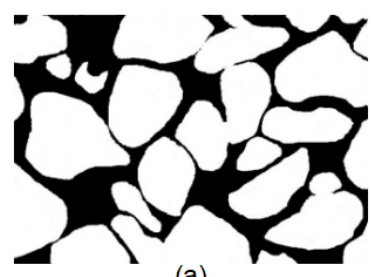

(a)

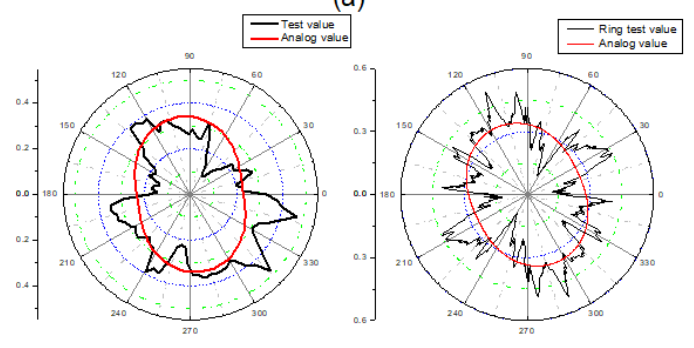

(b)

FIGURE VIII. SAMPLE 2 HORIZONTAL IMAGE AND DIRECTIONAL DISTRIBUTION CHART OF PORE ON LEVEL

\section{CONCLUSION}

Through observation of the porosity direction distribution maps of the two samples, it is discovered that the two samples are different from each other in their porosity distribution vertically and horizontally, close to be oval in their porosity direction distribution curves. In addition, in term of a same sample, there are small differences between the vertical porosity direction distribution and the horizontal porosity direction distribution. That sufficiently proves the sand from Tengger Desert is of anisotropic diffusion in its meso-structure of arrangement through natural sediments and it locates in different places in the desert. Different sediments will cause different anisotropy. As sand has anisotropy in its mesostructure, it is easier for the sand body to generate strains in the predominant direction of porosity distribution when it is under stress, which further causes such phenomena as slippage between soil layers, structural failure and so on. 


\section{ACKNOWLEDGMENT}

This work was financially supported by the National Natural Science Foundation of China (NO:5168050, NO:51669027) and the National Key R\&D Program of China (2017YFC0504400, 2017YFC0504404). These supports are gratefully acknowledged.

\section{REFERENCES}

[1] Zhongxuan YANG, Xiangsong LI, Haiyan MING, Study on the anisotropy and undrained shear properties of sand[J]. Journal of Shenzhen University, 100022618 ( 2009) 0220158206.

[2] Patent documents-CN103091212A. A new method for quantitative testing and analysis of fabric anisotropy.

[3] ODA M, KOISHIKAWA I. Effect of strength anisotropy on bearing capacity of shallow footing in a dense sand[J]. Soils and Foundations, 1979, 19(3):15-28.

[4] Oda.M. and Xazama. Microstructure of shear bands and its relation to the mechanisms of fatancy and failure of dense granular soils[J]. Geotechnique, 1998, 48(4):465-481.

[5] Alshibli K.A; El-Saidany H.A. Quantifying void ratio in granular materials using Voronoi tessellation[J]. Journal of Computing in Civil Engineering. 2001, 15(3):232-238.

[6] Yuanhai LI, Hehua ZHU, Shengli SHANGYE, Qiuli WANGYUE. Deformation field measurement of sand model test based on image correlation analysis[J]. Journal of geotechnical engineering, 2004, 26(1):36-41.

[7] Qinghao XU, Yi ZHAO, Jie FAN. Application of image analysis technology in soil microstructure research[J]. Friends of Science, 2008, 2(2): 147-148.

[8] VINCENT L, SOILLE P. Watersheds in digital spaces: An efficient algorithm based on immersion simulations[J]. IEEE Transactions on Patten Analysis and Machine Intelligence, 1991, 13(6): 583-598. 